\title{
Etnografando Helena: um caso de invenção de exclusão escolar
}

\section{Ethnographing Helena: a case of invention of school exclusion}

\section{Etnografando Helena: un caso de invención de la exclusión escolar}

\author{
Leonardo Carbonieri Campoy' \\ https://orcid.org/0000-0002-2686-0768
}

Sarha Cardoso²

https://orcid.org/0000-0002-58I2-0131

Resumo: Ao ser identificada como uma criança com problemas de aprendizado, Helena e sua família são lançadas em uma longa e incerta jornada em busca de um diagnóstico para a condição da menina. Acompanhamos esse processo por meio de uma etnografia baseada em observações, conversas com os protagonistas e uma análise de documentos médicos e escolares. A história de Helena serve como elemento empírico para uma reflexão crítica acerca da cultura da escolarização contemporânea. Argumentamos que os problemas de aprendizado da menina são indícios de um modelo escolar incapaz de lidar com as diferenças de subjetividades. A escola contemporânea ainda apresenta marcas de uma instituição fundada, no século XIX, sob o propósito da disciplinarização. Assim, a história de Helena é um caso que permite refletir sobre a inclusão escolar a contrapelo, isto é, por meio do entendimento dos mecanismos simbólicos e práticos que realizam a exclusão escolar. Como argumento conclusivo, o artigo aponta para as potencialidades que as etnografias e as subjetividades podem oferecer aos estudos de inclusão e de exclusão escolares.

Palavras-chave: Escolarização. Aprendizado. Crianças.

\begin{abstract}
Upon being identified as a child with learning problems, Helena and her family are launched on a long and uncertain journey in search of a diagnosis for the girl's condition. We follow this process through an ethnography based on observations, conversations with the protagonists and an analysis of medical and school documents. Helena's story serves as an empirical element for a critical reflection on the culture of contemporary schooling. We argue that this girl learning problems are signs of a school model incapable of dealing with differences in subjectivities. The contemporary school still bears the marks of an institution founded in the 19th century with the purpose of disciplining. Thus, Helena's story is a case that allows us to reflect on school inclusion against the grain, that is, through the understanding of the symbolic and practical mechanisms that carry out school exclusion. As a concluding argument, the article points to the potentialities that ethnographies and subjectivities can offer to studies on school inclusion and exclusion.
\end{abstract}

\footnotetext{
${ }^{1}$ Doutor em Sociologia e Antropologia pela Universidade Federal do Rio de Janeiro. Professor de Antropologia na PUCPR e no Profsocio-UFPR. E-mail: leocampoy@gmail.com

${ }^{2}$ Licenciada em Ciências Sociais pela PUCPR. Professora de Sociologia no Ensino Médio da rede pública de ensino do Paraná. E-mail: sarha-cardoso@hotmail.com
}

Olhar de professor, Ponta Grossa, v. 24, p. I-23, e-1845I.094, 2021.

Disponível em <https://revistas2.uepg.br/index.php/olhardeprofessor> 
Keywords: Schooling. Apprenticeship. Kids.

Resumen: Al ser identificada como una niña con problemas de aprendizaje, Helena y su familia se lanzan a un largo e incierto viaje en busca de un diagnóstico de la condición de la niña. Seguimos este proceso a través de una etnografía basada en observaciones, conversaciones con los protagonistas y un análisis de documentos médicos y escolares. La historia de Helena sirve como elemento empírico para una reflexión crítica sobre la cultura de la escolarización contemporánea. Sostenemos que los problemas de aprendizaje de las niñas son signos de un modelo escolar incapaz de abordar las diferencias en las subjetividades. La escuela contemporánea todavía lleva las marcas de una institución fundada en el siglo XIX con el propósito de disciplinar. Así, la historia de Helena es un caso que nos permite reflexionar sobre la inclusión escolar a contrapelo, es decir, a través de la comprensión de los mecanismos simbólicos y prácticos que llevan a cabo la exclusión escolar. Como argumento final, el artículo apunta a las potencialidades que las etnografías y subjetividades pueden ofrecer a los estudios sobre inclusión y exclusión escolar.

Palabras-clave: Enseñanza. Aprendizaje. Niños.

\section{Etnografia de Helena}

Pode-se afirmar que uma das riquezas da etnografia é a capacidade de reconhecer a autoridade das perspectivas de pessoas em condições subalternas em uma realidade particular (SPIVAK, 20I0). Técnica de pesquisa privilegiada em antropologia social, esse saber historicamente constituído a partir de estudos sobre grupos não-ocidentais geralmente posicionados nas franjas da modernidade, a etnografia tem sido utilizada para identificar e analisar etnias indígenas, gêneros dissonantes e sexualidades dominadas, corporalidades clivadas por racismos e toda sorte de preconceitos e discriminações, em suma, coletivos colocados à margem, aqueles que, em discursos oficiais, perderam as lutas históricas (ERIKSEN; NIELSEN, 2013).

A etnografia é útil para este tipo de estudos porque, primeiro, ela exige que o pesquisador se envolva na realidade dos seus interlocutores, acompanhando suas atividades, ouvindo suas histórias e participando, na medida do possível, daquilo que eles entendem por cotidiano e ordinário (DAS, 2020). Ao efetuar essa aproximação, segundo o pesquisador é levado a perceber as diferenças entre o que seus interlocutores fazem e pensam em relação ao que outros discursos indicam que eles fazem e pensam. Entre os antropólogos, esse movimento analítico de aproximação e distanciamento pode ser descrito pela máxima “familiarizar-se com o estranho para estranhar o familiar” (DAMATTA, I978).

A etnografia, portanto, permite perceber que a realidade social não é unívoca (PEIRANO, 2014). Eventos, situações e até mesmo ideias são articulados por cruzamentos de diferentes perspectivas, cada uma com seu quinhão de poder e todas elas, em alguma medida, em disputa.

Neste artigo, apresentamos os resultados de uma pesquisa etnográfica feita em realidade escolar. $\mathrm{Na}$ verdade, trata-se de uma etnografia de uma única menina. Helena ${ }^{3}$, na aurora de sua vida

\footnotetext{
${ }^{3}$ Nome fictício. Importante assinalar que a pesquisa com Helena foi autorizada pela e feita com sua mãe e principal cuidadora, como ficará claro a seguir.
} 
escolar, foi classificada pela escola como uma aluna com problemas de aprendizado. Exigiu-se de sua família, a partir daí, a instalação de um verdadeiro périplo em busca de um diagnóstico que confirmasse suas dificuldades cognitivas. Todavia, os profissionais de saúde não identificavam na menina nenhum problema ou barreira para seu desenvolvimento intelectual. Mesmo assim, as escolas de Helena insistiam que ela tinha dificuldades que escapavam do âmbito pedagógico. Enquanto esses eventos se desenrolavam, a família de Helena se angustiava.

O que essa história pode revelar sobre a realidade escolar? Será que as perspectivas médicas e escolares condizem com a subjetividade de Helena? Como entender o modo pelo qual Helena foi interpretada por suas escolas? Como interpretar, enfim, o jogo de perspectivas sobre Helena?

Nosso objetivo com essa pesquisa não foi identificar o ponto de vista de Helena, mas o de perceber o jogo de perspectivas no qual ela e sua família foram lançadas. Estas perspectivas, que operam tanto na ordem do discurso quanto na da ação, mediam o que se pode entender, pelo ponto de vista relacional da antropologia, por inclusão e exclusão escolares. Schuch, Víctora e Silva (2018) observam que, do ponto de vista da antropologia, não se trata de endossar uma noção de inclusão ou ainda, de atestar a eficiência de uma política de inclusão, uma vez que, por meio da pesquisa etnográfica, percebese que os atores e as práticas mobilizados em situações de inclusão são sempre mais heterogêneos e cambiantes do que as molduras fixas dos discursos institucionais supõem. Ou seja, os fatores determinantes de ações de inclusão escolar não podem ser identificados exclusivamente na escola, na família ou, em casos de crianças com laudos médicos, em instituições de saúde. As ações de inclusão escolar, assim entendidas, são tramas relacionais costuradas por essas três pontas - escola, família e instituições de saúde - e considerando as heterogeneidades de ideias, pessoas e ações que elas concentram. Portanto, no esforço de elucidar as políticas e ações de inclusão escolar de crianças com deficiência, a antropologia pode contribuir com essa perspectiva relacional, a qual, antes de se deter em apenas uma das pontas que exercem ação sobre a criança, analisa os cruzamentos - ou o que denominamos acima de jogo - de perspectivas que certamente incidem sobre elas, as crianças (CARNIEL, 2018).

Entendemos que os problemas de Helena não são responsabilidades exclusivas dela e de seus cuidadores, mas, antes, são o resultado de concepções teóricas, práticas e institucionais que enredaram, como que a encaixotando, Helena. Nas linhas a seguir, procuramos desencaixotar Helena, identificando e analisando as linhas de força que a empurraram para fora da normalidade escolar. Nosso texto, então, oferece uma reflexão sobre a inclusão escolar por meio da elucidação de uma manifestação de sua outra face, tal como a antropologia social, especialmente a partir da perspectiva de Douglas (2010) recomenda: quando ela não acontece, quando ela é evitada, quando, na verdade, a realidade é de exclusão escolar. 


\section{A presença da ausência do diagnóstico}

Helena é minha sobrinha ${ }^{4}$. Com a anuência de todos os envolvidos, tomo aqui a liberdade de, por meio de relatos da família e análise de documentos de encaminhamento médico, bem como registros pedagógicos, descrever etnograficamente o processo de diagnóstico de minha sobrinha ${ }^{5}$, caso que venho acompanhando desde seu ingresso no ambiente escolar, especialmente seu momento de introdução ao ensino fundamental, que deu início a seu processo de alfabetização.

Figura I - Capa da agenda escolar desenhada por Helena: um autorretrato que a representa realizando uma acrobacia no brinquedo da escola, com seu corpo e tranças de ponta-cabeça

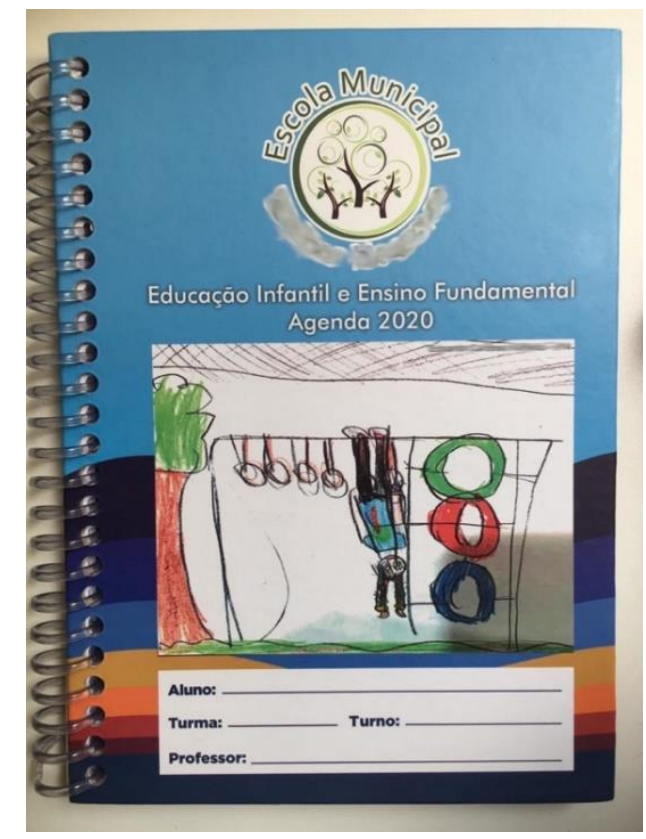

Fonte: os autores, 2021 .

O início da educação básica na vida de Helena, com cinco anos, em seu ingresso no primeiro ano do ensino fundamental, já é marcado por observações que partiram da escola sobre a forma com

\footnotetext{
${ }^{4}$ A etnografia de Helena faz parte do trabalho de conclusão de curso de graduação em licenciatura em ciências sociais, na Pontifícia Universidade Católica do Paraná, de Sarha Cardoso, orientado pelo professor da casa, Leonardo Carbonieri Campoy. Considerando essa particularidade, o caráter autoral da pesquisa etnográfica e o fato de Helena ser sobrinha de Sarha, decidimos manter aqui a narrativa em primeira pessoa. De todo modo, todo o artigo foi escrito e revisado a quatro mãos.

${ }^{5}$ A pesquisa realizada por Sarha pode ser concebida como uma espécie de autoetnografia, já que seus interlocutores são pessoas de sua própria família. Importante esclarecer que, inicialmente, o objetivo era realizar a pesquisa com alguém pessoalmente desvinculado de Sarha. No entanto, as medidas de prevenção à COVID19, em razão da pandemia, nos obrigaram a alterar os planos iniciais e realizar a pesquisa com Helena. Sobre as possibilidades e limites da autoetnografia, ver Gama (2020).
} 
que a criança se comportava. As antigas agendas e documentos da escola são mantidos e preservados por sua mãe, minha irmã, que sempre acompanhou a vida escolar da filha com muita dedicação e atenção, mantendo sempre os registros vindos da escola organizados e arquivados.

Logo após o início do ano escolar, o dia de II de abril de 2017 marcou a primeira queixa da professora, registrada na agenda de Helena, que manifestava uma preocupação acerca da atenção da criança. Escrito à mão, o recado veio assim: "Olá mãe. Se puder trocar o estojo da Helena, pois o mesmo é lindo, mas ocupa a mesa inteira e acaba atrapalhando a Lena! Quando possível. Beijos, professora"

Figura 2 - Recado da professora para a mãe na agenda de Helena. $O$ primeiro de muitos que a mãe recebeu de diferentes professoras, pedagogas e gestoras escolares.
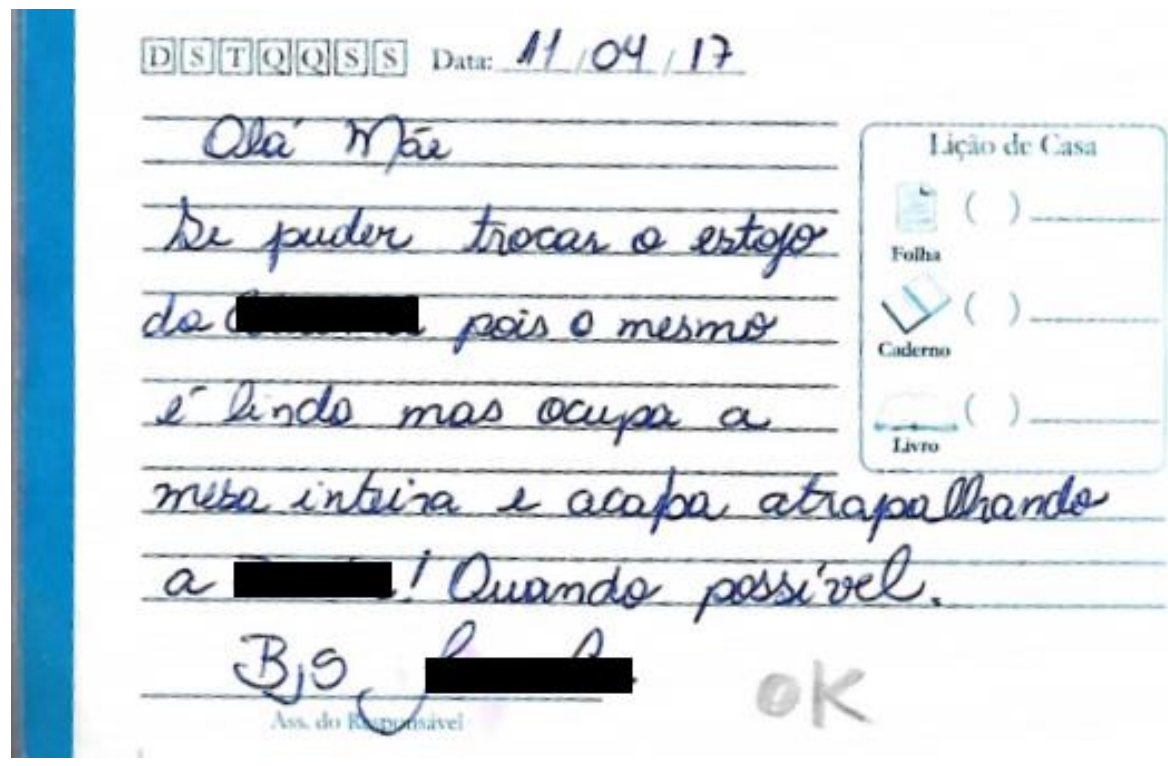

Fonte: os autores, 2021

A família atendeu prontamente ao pedido da professora, substituindo o estojo por um menor e menos colorido. Ainda assim, um novo recado na agenda, registrado pouco menos de dois meses depois, 05 de junho, solicitava que a mãe de Helena fosse até à escola para conversar com a pedagoga. Essa visita marcou o primeiro encaminhamento médico solicitado pela escola, para identificar o que fazia com que Helena fosse tão distraída, o que tornava a organização dos lápis em seu estojo mais interessante do que a aula.

Aqui começou a jornada de Helena e sua família no périplo do diagnóstico requerido pela escola. $\mathrm{O}$ acompanhamento médico de Helena foi inteiramente feito na rede pública de saúde, o que acabou tornando tudo um tanto mais burocrático, uma vez que o sistema necessita de encaminhamentos médicos prévios para que o processo de diagnóstico pudesse seguir. De qualquer forma, essa primeira visita ao médico não trouxe grandes contribuições na busca dos motivos que

Olhar de professor, Ponta Grossa, v. 24, p. I-23, e- I845I.094, 202 I.

Disponível em <https://revistas2.uepg.br/index.php/olhardeprofessor> 
tanto distraiam a criança. A passagem pelo pediatra foi breve e Helena foi dispensada, uma vez que o médico alegou que não havia nada de errado com ela. As duas visitas seguintes tiveram o mesmo resultado. Quase como um ciclo, naquele ano a escola a encaminhou para o hospital três vezes e, em todas, os pediatras a dispensaram alegando a mesma constatação, a de que criança não apresentava problemas.

Passou a ser perceptível pela família, então, um embate de interesses entre os médicos, que negavam encaminhar Helena para consultar com outros especialistas, e a escola, que solicitava e buscava sem descanso uma justificativa sobre os problemas acerca de seu desempenho escolar. Em uma conversa sobre o atendimento médico, a mãe da criança me relatou que "um dos médicos me disse que tá na moda, a escola fica mandando as crianças pra consulta procurando pelo em ovo", em tom indignado, como se o médico não estivesse dando atenção suficiente aos problemas identificados pela escola.

O ano escolar passou e, em 2018, Helena ingressou em uma nova escola, mais próxima de onde sua família residia no momento, uma quadra de distância de sua casa. Uma escola menor e mais acolhedora: "até hoje é a escola da vida dela, né Lena?", sua mãe me disse enquanto tomávamos café, em uma tarde comum. De qualquer forma, a nova escola também não tardou em queixar-se sobre o comportamento distraído de Helena e, pela quarta vez, uma nova visita ao pediatra foi realizada.

Para o alívio da mãe, no dia 25 de junho daquele ano, uma médica finalmente reconheceu o problema identificado pela escola. Nesse momento, Helena já tinha 7 anos completos e foi encaminhada à fonoaudióloga. No receituário médico encontra-se o seguinte registro: “À fonoaudiologia. Por dificuldade na escola, linguagem infantilizada, falta de atenção e concentração, solicito avaliação audiométrica".

Figura 3 - A requisição de avaliação audiométrica de Helena.

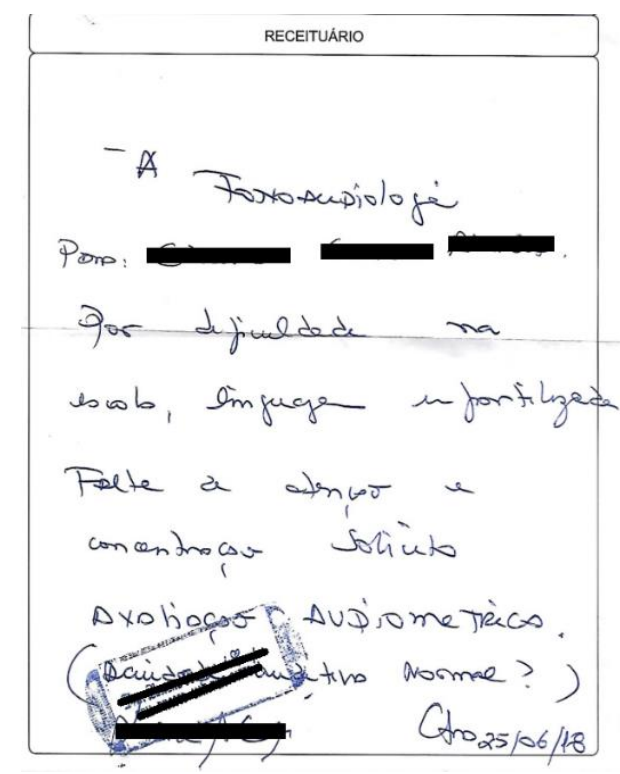

Olhar de professor, Ponta Grossa, v. 24, p. I-23, e-18451.094, 2021.

Disponível em <https://revistas2.uepg.br/index.php/olhardeprofessor> 
Fonte: os autores, 2021.

Enquanto aguardava na fila do sistema público de saúde para fazer o exame de audiometria tonal - que veio a ser realizado no ano seguinte, no dia II de fevereiro de 2019 -, o acompanhamento com a fonoaudióloga passou a ser semanal. No registro médico, o resultado do exame indica que os limiares auditivos de Helena são normais. Após um ano de visitas à fonoaudióloga, a "fala infantilizada" de Helena foi corrigida e ela ganhou alta médica.

Em 2019, um novo ano escolar começou e, com ele, novamente foi solicitada pela escola uma visita da mãe. Uma conversa com a professora e a pedagoga, que levou aproximadamente uma hora e meia, traduziu-se em uma mãe que chegou em casa com olhar preocupado e triste. A alta da fonoaudióloga, que esperançosamente podia significar para a família o fim da procura médica para a solução do suposto mau desempenho escolar de Helena, tornou-se efêmera diante de novas solicitações de avaliação psicológica, neurológica e oftalmológica.

Sobre a visão de Helena, o laudo médico do dia II de março registrou que a criança tem "ausência de refração significativa que precise ser prescrito", ou seja, não existem problemas com seus olhos. O comprovante de inclusão registra também que, no dia 27 de março, foi o momento em que a criança ingressou na fila de espera de avaliação psicológica e consulta com neurologia pediátrica.

Com todo esse processo acontecendo provavelmente a tempo demais, a angústia da família, especialmente da mãe de Helena, tornou-se cada vez mais crescente. A criança, que não demonstrava comportamentos que destoavam das outras crianças da família, fazia com que todo esse périplo médico e escolar fosse ainda mais intrigante para seus cuidadores. À época, perguntávamo-nos "o que teria ela, afinal? Já se passa tanto tempo e não temos uma resposta!".

Helena tem uma relação muito próxima com seus familiares. Mora no mesmo terreno que seu avô, tia e prima por parte de pai e, ao lado da mãe, é muito apegada com seus avós e tias. Ainda conta com três primos mais velhos que ela, os quais não demonstravam grandes diferenças de comportamento em relação à Helena quando tinham sua idade. Sua tia e madrinha, mãe desses três primos, descreve-a como uma criança doce e bem-humorada - "ela é dispersa com assuntos que não são do seu interesse, porém muito atenta aos que são" - além de ter similaridades com seu filho mais velho, que não era tão bom para fazer amigos e adorava jogos eletrônicos - "ela tem muitas coisas em comum com o Saullo6". Saullo, por sua vez, que está com 20 anos no momento em que escrevemos essas linhas, identifica-se muito com Helena. Sempre que se encontram, engajam em conversas sobre jogos, já que o atualmente favorito de Helena também é o mesmo de Saullo quando tinha sua idade.

\footnotetext{
${ }^{6}$ Nome fictício.
}

Olhar de professor, Ponta Grossa, v. 24, p. I-23, e-18451.094, 2021.

Disponível em <https://revistas2.uepg.br/index.php/olhardeprofessor> 
Em momentos como este, é recorrente que Saullo relembre o quanto foi parecido com Helena quando criança. Entretanto, seu desempenho escolar não parecia chamar atenção como o de Helena, "o que faz tudo isso parecer mais confuso ainda", ele diz. Helena, a quarta de cinco netos de seus avós, é encarada como uma menina calma e meiga, "é muito criativa e esperta, essa menina”, descreveu a avó, "tudo isso (processo de diagnóstico) me deixa muito ansiosa, preocupada, frustrada, tenho medo dela ter algum problema que eu não consigo perceber" disse, tentando buscar na criança algo que pudesse ser claro o suficiente para que pudesse ser considerado um problema.

Dentre as características mais marcantes de Helena, a que chama mais minha atenção é sua criatividade. Desde muito cedo, sua atividade favorita é desenhar. Em um concurso para escolher qual seria a capa da agenda de sua escola no ano seguinte, concorrendo com todos os outros estudantes da escola, seu desenho foi o escolhido como vencedor (figura I). Sempre criando histórias em quadrinhos e animações, o desenho tem sido seu favorito passatempo, praticado principalmente em um aplicativo no celular para esse fim.

Após mais de dois anos em busca dos motivos clínicos que supostamente faziam com que ela tivesse um desempenho escolar abaixo do esperado, Helena passou a realizar consultas semanais a partir do serviço-escola de uma universidade da cidade, onde os graduandos do curso de psicologia tinham como estágio a prática de atendimentos psicológicos aberto à comunidade e com valor acessível, na tentativa de adiantar o processo enquanto aguardava a avaliação neurológica, uma vez que a fila de espera no SUS (Sistema Único de Saúde) para ambas as especialidades, psicologia e neurologia, era demasiadamente extensa.

Durante um ano Helena frequentou a clínica psicológica da universidade. De tempos em tempos, a psicóloga tinha conversas com a mãe da criança, procurando saber mais sobre seu comportamento em casa e na escola. No final dessa jornada, de dois semestres, a psicóloga que acompanhou Helena não tinha nenhuma observação preocupante a fazer. Disse que existia a possibilidade de avaliá-la de maneira psiconeurológica, mas não demonstrou urgência em fazê-lo e, no fim de seus encontros, registrou que "em geral, não parece ter nada demais".

Finalmente, logo no início de 2020, no dia 13 de fevereiro, uma pré-consulta neurológica foi agendada. Nela, a mãe recebeu dois questionários. Um para que ela preenchesse e o outro para a escola. Um dos questionários tinha como objetivo realizar o SNAP-IV, uma avaliação que investiga os sintomas de déficit de atenção/hiperatividade (TDAH), bem como o transtorno desafiador de oposição (TOD), que são transtornos de aprendizagem infantil de acordo com o cânone psiquiátrico (COSTA; PAULA; MALLOY-DINIZ; ROMANO-SILVA; MIRANDA, 2019 p. 737).

Esse questionário conta com 26 afirmações sobre o comportamento da criança, como a oitava: "É distraído por estímulos alheios”; a décima quinta: "Fala em demasia”; a vigésima: "Discute com 
adultos"; a vigésima quarta: "É sensível ou facilmente incomodado pelos outros". Dentre essas afirmações, é dever do professor e dos pais marcar se elas contemplam o comportamento da criança como "nem um pouco", "um pouco", "bastante" ou "demais".

Nesse ano, 2020, Helena mudou novamente de escola, uma vez que, ao terem trocado de endereço mais uma vez, a antiga ficava muito longe de sua atual casa, o que resultou em um novo ambiente e uma nova professora. De qualquer forma, os questionários são preenchidos e, apesar da professora conhecer Helena por pouco tempo, a escola nova já estava informada sobre a recorrente tentativa em diagnosticar seu baixo desempenho e distração. Ainda assim, mãe e professora preencheram os questionários de forma muito similar, não tendo grandes discordâncias sobre o comportamento de Helena. A resposta "bastante" foi dada para duas perguntas e em nenhuma vez a alternativa "demais" foi escolhida pela mãe ou pela professora.

Figura 4 - Questionário respondido pela mãe de Helena.

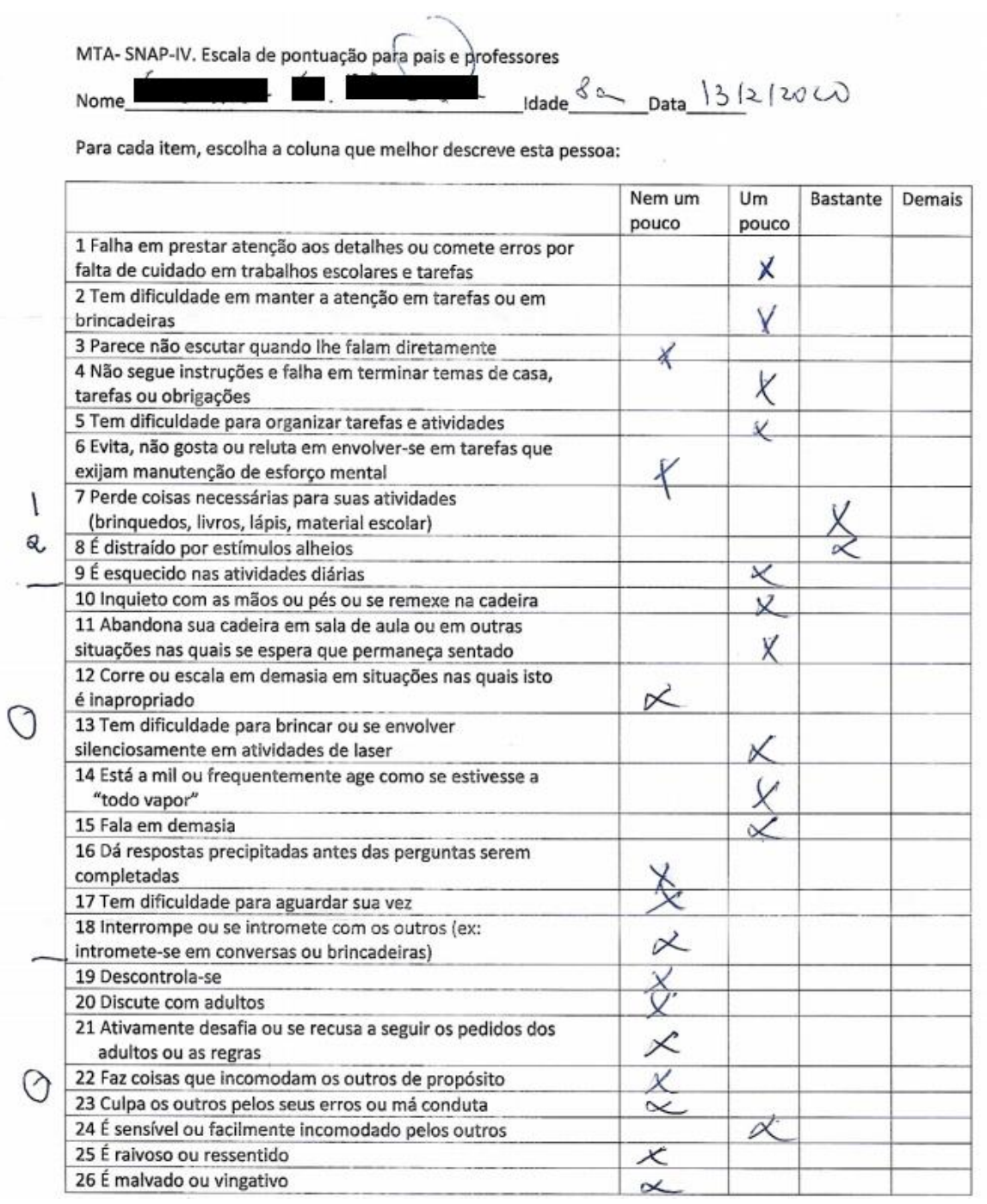


Fonte: os autores, 2021.

Vale ressaltar que, juntamente a todo o processo de diagnóstico que seguia acontecendo, 2020 é o ano em que Helena ingressou no quarto ano do ensino fundamental ainda apresentando grande dificuldade para ler e escrever, já tendo deixado para trás os anos que supostamente deveriam formar as bases de sua alfabetização. Nesse ponto, o sistema escolar, em razão da progressão curricular, intuitivamente já assume que Helena deveria estar alfabetizada, apesar de essa não ser a realidade observada em suas habilidades. Neste momento, já se completavam 3 anos nesse processo de "em busca de um diagnóstico perdido" e a exaustão da família, principalmente da mãe, era crescente. "Em todos os anos que ela passou (na escola), passaram a mão na cabeça dela, tá alfabetizada, passa de ano, quando ela não tá!", relatou a mãe em uma fala em tom angustiado.

A pandemia de Covid-19 encurralou toda essa situação para dentro da casa da família ${ }^{7}$. As aulas foram suspensas em meados de março, fazendo com que o ensino escolar passasse a acontecer dentro de casa, de maneira remota. Apostilas foram entregues para que as atividades fossem realizadas com o auxílio dos pais, com prazo de retorno de entrega para a escola previamente estipulado. Helena passou a dividir seu espaço de aprendizagem com o local em que dormia, brincava e realizava suas atividades cotidianas, além de compartilhá-lo agora com sua irmã mais nova, de três anos de idade, e seus pais, bem como de estar no mesmo terreno em que sua tia, avô paterno e prima, os quais visitavam constantemente sua casa.

Após 5 meses de ensino remoto, no dia 25 de agosto de 2020, a professora responsável pela turma de Helena, já com nove anos completos, enviou um relatório escolar para família, que viria a ser mostrado para o médico neurologista. No relatório consta:

Devido a pandemia do COVID-19 e respeitando a lei de distanciamento social, a Secretaria Municipal de Educação tem disponibilizado tele aulas por canal aberto ou Youtube. A escola tem realizado entrega de atividades quinzenais, aos responsáveis dos estudantes. A aluna Helena, tem realizado em casa, as atividades propostas com auxílio dos familiares. Realiza leitura de pequenos textos, em caixa alta, com ajuda. Interpreta histórias em quadrinhos e contos de fadas, nos demais textos necessita de auxílio. Produz pequenos textos narrativos e história em quadrinhos com auxílio para organizar suas ideias. Percebo na escrita, que Helena realiza algumas omissões e trocas de letras, inclusive do seu nome e sobrenome. Realiza as operações de adição e subtração simples na ordem da unidade. Reconhece a maioria dos números até 999. Nas situações problemas, necessita de auxílio para a compreensão do que é solicitado e, geralmente, precisa de material concreto ou desenho para encontrar a resposta. Nos componentes curriculares de História, Geografia e Ciências, precisa de explicação individual, retomando o conteúdo, utilizando de outros exemplos para

\footnotetext{
${ }^{7}$ Para fins de contextualização do caso de Helena, de acordo com pesquisa feita pela fundação Carlos Chagas, nos primeiros meses da pandemia (março a maio de 2020), 81,9\% dos alunos da educação básica deixaram de ir à escola no Brasil como resultado das medidas de contenção da propagação do vírus: https://www.fcc.org.br/fcc/educacao-pesquisa/educacao-escolar-em-tempos-de-pandemia-informe-n-I. Acesso em: 20 dez. 2021.
} 
compreensão, necessitando de auxílio para responder as atividades. Em sala de aula, costumava distrair-se facilmente, necessitando resgatar sua atenção constantemente para concluir as tarefas escolares. No recreio, comportava-se adequadamente, mas, demonstra um pouco de dificuldade em fazer amizade com os colegas, devido à insegurança.

Ainda nesse processo de encaminhamentos e consultas sem fim, um exame de sangue é realizado também em agosto de 2020. Até este momento, Helena já havia realizado consultas que constavam que ela não demonstrava problemas de audição nem visão. $O$ resultado desse exame vem para somar em uma equação que demonstra que, fisicamente, não existem problemas com essa ela, além de já ter recebido alta da fonoaudióloga, uma vez que já havia corrigido sua "fala infantil", bem como acompanhamento psicológico, no qual a profissional alega que em "geral, não havia nada muito preocupante" com Helena.

No meio desse processo de idas ao médico e atividades escolares, o tempo livre de Helena era preenchido por seus desenhos e criações, mas, principalmente, jogos no celular. Dentre suas escolhas favoritas, um jogo colaborativo online, que demandava escrita e leitura na caixa de mensagens, tornou-se seu favorito. Enquanto jogava, em meio à pandemia e fora do ambiente escolar, Helena passou a treinar sua leitura e escrita, apresentando uma grande melhora em sua alfabetização, bem diferente dos parcos progressos que teve na escola ${ }^{8}$. Quando perguntei para ela o que achava sobre a escola, ela disse que "é legal...minha parte favorita é quando eu termino de escrever tudo que tá no quadro". Ou seja, a melhor parte da aula é quando ela acaba.

A condição escolar, que fazia com que ela ficasse por horas sentada em fileiras, pareceu-lhe monótono e pouco estimulante. Chamaram-lhe a atenção algumas vezes por estar dormindo em sala. Como já mencionado, Helena parece sim ser uma criança dispersa quando se trata de assuntos com os quais ela não tem interesse. Assim, o momento em que seu interesse pela leitura e escrita surgiu foi quando o universo escolar deixou de ser uma parte predominante de sua rotina. Sem professores, carteiras enfileiradas ou sala de aula. Em um jogo em um celular, sem a mediação de educadoras, sua alfabetização progrediu sensivelmente.

O dia 02 de setembro de 2020 marca a tão aguardada consulta de Helena com um neurologista. Após suas intermináveis passagens por especialidades médicas diferentes durante os últimos três anos, finalmente uma provável resposta para o problema do estojo de lápis apareceu.

Naquela manhã, Helena, sua mãe e sua irmã mais nova chegaram em minha casa para que a última ficasse sob os cuidados de meus pais e não atrapalhasse o andamento da consulta tão aguardada

\footnotetext{
${ }^{8} \mathrm{O}$ desenvolvimento da alfabetização de Helena por meio dos jogos digitais condiz com o que a literatura sobre o tema tem indicado, isto é, que estes aplicativos podem, de fato, ter um impacto positivo nos processos de aprendizado (BREUER; BENTE, 20I0; FARIA; COLPANI, 20I8; SILVA; REBOUÇAS, 20I8).
} 
pela escola - "vai lá pro neurologista. Neurologista, neurologista, neurologista. Eles só falam sobre isso" - expressou a mãe sobre a insistência e antecipação da escola quanto a tal consulta.

Quando retornaram, o tom triste na voz de minha irmã denunciava uma mãe preocupada, - "a médica disse que pode ser um leve grau de autismo"” - revelou. Com uma pasta escolar amarela em mãos, já larga pela quantidade de papeis que carregava, agora ainda mais cheia com o documento que formalizava o retorno em 40 dias e novos encaminhamentos: comprovantes de inclusão para fila de espera para ressonância magnética de crânio e eletroencefalograma, bem como um retorno para avaliação psicológica em um centro especializado. Além disso, uma receita de remédio, um psicotrópico utilizado para tratamento de esquizofrenia, para auxiliar na "organização de pensamentos" e ainda “ajudar ela a dormir", mesmo que Helena não tivesse problemas com insônia. De qualquer forma, nenhum dos papeis formalizava oficialmente o diagnóstico dito pela médica, já que, para tanto, os exames requeridos tinham de ser realizados.

No momento em que minha irmã contava sobre o diagnóstico, Helena abriu a porta do quarto um tanto quanto empolgada, - "eu sou autista, Sarha!" - disse enquanto sorria. Contraditória a essa informação que aparentemente deixava Helena empolgada, no entanto, o laudo médico enviado à escola consistia no diagnóstico de Transtorno de Déficit de Atenção e Hiperatividade (TDAH) ${ }^{10}$.

No dia seguinte, contudo, a mãe dela me contou que, logo depois de chegar em sua casa naquele dia, Helena estava cabisbaixa; - "ela me chamou no quarto e perguntou: é normal ser autista, mãe?".

As informações contrastantes passadas pela médica à família e à escola despertaram sentimentos ainda mais confusos: "ela não tem problema relacionado a nada físico, nenhum, nada...e os exames que podiam estar me confirmando qualquer coisa vão demorar", declarou a mãe, preocupada com a fila de espera para os exames: "Não é só uma consulta (que pode confirmar um diagnóstico),

\footnotetext{
${ }^{9}$ De acordo com o DSM-V (20|3), que é a quinta edição do Manual Diagnóstico e Estatístico de Transtornos Mentais da Associação Americana de Psiquiatria, documento de referência global para a saúde mental, o autismo é um transtorno do desenvolvimento marcado por déficits socioemocionais que impactam as relações sociais, a comunicação e o aprendizado. Apesar da precisão com que o DSM o classifica, o diagnóstico de autismo não é simples e, muitas vezes, acaba sendo oferecido às famílias não porque o médico tem certeza, mas para dar fim às buscas angustiantes por uma elucidação de uma condição incerta e fugidia da criança, como parece ter sido o caso de Helena. Para uma leitura antropológica do diagnóstico de autismo, ver Campoy, 2017.

${ }^{10}$ No Brasil, em casos em que a escola aponta dificuldades de aprendizado de alunos que supostamente exigiram intervenção médica, a confirmação do diagnóstico de TDAH tem sido o desfecho mais comum (GARBARINO, 202I). Apesar das polêmicas relacionadas ao seu diagnóstico, o TDAH, caracterizado por hiperatividade e desatenção, demanda estratégias pedagógicas específicas e treinamento especializado do educador, como argumentam Bonadio e Mori (2013). Para uma etnografia das estratégias pedagógicas para crianças diagnosticadas com TDAH, ver Borba (202I).
} 
porque com só uma consulta médico nenhum vai colocar um CID II desse, tanto que não foi esse CID que ela colocou, foi outro, foi de déficit de aprendizagem, enquanto que pra mim ela diz que é um autismo leve, mas na hora de assinar, assina outra coisa”, ela disse, quase sem fôlego, em tom alto, e continuou: "pra mim não faz diferença o CID que eles vão colocar lá, sinceramente. $O$ número e as letrinhas que eles põem pra mim como mãe não faz diferença nenhuma. Eu quero que minha filha saiba! Aprenda!", enfatizando as duas últimas palavras, quase gritando.

Com 2020 chegando ao fim, o ano escolar acabou e, mesmo não acompanhando o desempenho dos colegas de sua classe, de acordo com a expectativa da escola, Helena passou de série, do quarto para o quinto ano do ensino fundamental. Já em 2021, a possibilidade do retorno às aulas presenciais acendeu uma esperança, tanto para família quanto para criança, sugerindo que as experiências escolares de Helena poderiam ser mais agradáveis. Contudo, logo essa esperança foi dissipada, justamente quando as aulas presenciais foram canceladas novamente em razão do agravamento da pandemia no país. Neste contexto, no dia em que soube que as aulas retornariam para o modo remoto, a mãe de Helena brincou comigo: "lá na minha faculdade de mãe fugi essa aula, alfabetizar filho em casa, gazeei, porque não sei, não tenho gabarito pra isso".

Todas as questões e implicações acerca da condição de Helena parecem resultar em desconfianças da escola. A problemática sobre a aprendizagem da criança iniciou-se quando ela tinha cinco anos. Agora, com quase dez, as medidas que foram tomadas para solucionar esses problemas parecem dificultar ainda mais sua jornada. Em uma conversa casual em minha casa, perguntei para minha irmã como ela estava lidando com relação ao medicamento. Ela respondeu que,

Tô dando, contra minha vontade, contra vontade da família, porque a nossa ideia de família não é medicar, não é. Mas tô fazendo, pra não dizer que tô indo contra o médico e pedagoga, e todos os tipos de profissionais, então...

Pausa por alguns instantes, já visivelmente abalada:

E cadê o resultado? O que me interessa é o resultado, é o aprendizado. Superou o que? Nada. Pior, só aumentou. Aumentou com a pandemia e mais ainda com esse diagnóstico, que agora ela pode aprender ou não, que tanto faz. Tá aprovada. E vamos continuar acompanhando.

A última frase foi lançada em um tom irônico em relação à postura das escolas, uma vez que havia recebido em recente reunião escolar a informação que Helena passaria de ano.

\footnotetext{
" A CID é a Classificação Estatística Internacional de Doenças e Problemas Relacionados à Saúde, um código internacional preparado e gerido pela Organização Mundial da Saúde (OMS). A edição em vigor é a décima e a décima primeira está sendo finalizada.
} 
Engatada no assunto, a conversa passou a ser sobre as impressões que a escola vem deixando com relação à forma que lidam com crianças que têm um diagnóstico. Ela me contou que sua dentista comentou com ela que a escola atrapalhou o desempenho de seu filho, que tinha um problema de audição, sempre tratando-o de forma diferente por ter dificuldade em acompanhar as aulas e ainda, que no caso da sobrinha de sua dentista - que tem a mesma idade e as mesmas, se não ainda mais evidentes, dificuldades que às de Helena com relação ao desempenho escolar -, a escola utiliza-se do diagnóstico de bronquite da menina para justificar seus desajustes: "não tem o diagnóstico do autismo, mas ela tem bronquite, ah, pronto. A escola já se apega nisso. Não aprendeu, não veio, por quê? Bronquite".

Na perspectiva da mãe, o que antes pareciam apenas procedimentos de cuidado e preocupação das escolas com relação às condições de aprendizagem da filha, agora parecem se traduzir em formas de passar seus problemas para frente sem que tenham que tomar responsabilidade sobre sua aprendizagem 12 :

Anteciparam que vão aprovar ela de qualquer forma. Porque esse diagnóstico veio então pra... pra prejudicar mais. Vamos aprovar a Helena porque ela tem um déficit de aprendizagem, porque ela tem um autismo, então ela vai ser aprovada e o próximo colégio que se responsabilize, que continue acompanhando. Assim a professora me disse, uma semana atrás. Quer dizer, eles já 'tão empurrando a Helena com a barriga há 3, 4 anos... fiquei desesperada, Sarha.

A aflição da mãe não resulta de preocupações com as condições de saúde da filha, mas advém do entendimento de que as escolas não parecem estar dispostas a assumir a responsabilidade para com o aprendizado de Helena. Ela não está criticando exatamente o fato da filha 'passar de ano', mas sim o de que sua filha é aprovada 'de qualquer forma', ou seja, sem reter o que deveria aprender naquele período escolar em específico. Portanto, na perspectiva da mãe, as escolas identificaram uma dificuldade de aprendizado que supostamente teria origem em condições pessoais de Helena e, a partir daí, teriam se eximido das atribuições de participar do processo de ensino da menina. É como se, na divisão do trabalho de ensino e aprendizagem, a escola estivesse afirmando sua impossibilidade de realizar suas atribuições porque as condições individuais da criança não permitem. A responsabilidade recai sobre Helena, obviamente, e sua mãe, principalmente. Assim, na perspectiva da mãe, as escolas não procuraram articular estratégias pedagógicas para incluir Helena, isto é, formas de ensino que,

\footnotetext{
${ }^{12}$ As reações da mãe de Helena em relação à escola ressoam o que pesquisas com mães de crianças com deficiência no Brasil sublinham profusamente: elas parecem desconfiar das instituições de cuidado. As mães parecem ter a constante impressão de que os profissionais de saúde e de educação não estão preparados para cuidar de suas crianças ou a de que as instituições não têm condições de oferecer o cuidado que elas desejam e entendem que suas crianças merecem. Sobre as mães de crianças com deficiência pela perspectiva da psicologia, ver Bosa e Schmidt (2007). Já pela análise antropológica, ver Fietz (2020).
} 
mesmo diante de dificuldades nítidas e diagnósticos inexistentes, pudessem estimular o aprendizado da menina. Antes, etiquetaram Helena como um caso de ordem médica e familiar que não competia à abordagem escolar. Não seria essa postura uma estratégia de exclusão escolar mascarada de preocupação com as condições de saúde e de desenvolvimento da criança?

\section{A escola e suas lacunas}

A insistente busca no que pode haver de errado com Helena nos possibilita refletir sobre o papel da escola desde a perspectiva antropológica. A etnografia da trajetória de Helena lançou luz empírica nos processos pelos quais as subjetividades e corpos que compõem a escola tendem a se adaptar ou não às expectativas desta instituição. Sendo mais incisivos no argumento, afirmamos que a subjetividade de Helena evidencia uma incompatibilidade com o sistema escolar e, assim, ilustra uma face da crise escolar tal como denunciada pela antropóloga Paula Sibilia (2012). A autora afirma que a escola contemporânea está marcada por um desencaixe entre o que a instituição oferece e as subjetividades dos jovens que recebe. Seguindo Foucault (20I0), a autora argumenta que a escola foi constituída ao longo do século XIX como engrenagem fundamental da sociedade disciplinar. Sua função era a de produzir subjetividades exemplares ao corpo social idealizado pela época: indivíduos controlados, tanto no sentido de dominar seus desejos particulares quanto no de respeitar a ordem coletiva. Entretanto, a partir da segunda metade do século $X X$, as bases da sociedade disciplinar vão sendo paulatinamente dilapidadas pelo desenvolvimento e inserção nos cotidianos dos meios de comunicação e de entretenimento, do consumo, das estratégias neoliberais de flexibilização e empreendedorismo de si e, finalmente, pelo imperativo da libertação individual. Daí o desencaixe. Enquanto os jovens contemporâneos elaboram seus horizontes de expectativas de acordo com as condições midiáticas e neoliberais, a escola ainda se esforça para encaixá-los na sociedade disciplinar do XIX e início do XX.

A jornada de Helena é delineada por esses desencaixes entre escola e jovens para os quais Sibilia chama a atenção. A subjetividade dela apresentou um problema que a escola não soube resolver ou, o que dá no mesmo, precisou mobilizar o aparato biomédico para dar conta. Neste sentido, a dificuldade dos diferentes profissionais de saúde em determinar seu diagnóstico nos parece significativa. Enquanto várias especialidades e exames biomédicos indicavam que estava tudo bem com a menina, as diferentes escolas pelas quais Helena passou insistiam que ela era incapaz de realizar um desenvolvimento cognitivo adequado de suas habilidades de aprendizado. Mais ainda: é notável que, em razão da pandemia de COVID-19, quando Helena esteve ausente do ambiente escolar, sua alfabetização desenvolveu-se qualitativamente a partir do seu uso de jogos digitais que exigiam leitura e escrita. 
Diante desta confluência de fatores, não podemos nos furtar de levantar a indagação: afinal de contas, de quem é o problema? Para quem Helena é um problema?

Apesar das diferentes e bem-vindas renovações das teorias pedagógicas ao longo do século $\mathrm{XX}$, a história de Helena nos autoriza a sugerir que, em termos práticos, o modelo escolar concebido no século XIX pela necessidade de instrução básica para que operários pudessem manusear máquinas, professor à frente de fileiras de alunos sentados, observando e (supostamente) absorvendo, ainda é adotado para educar as crianças. Por extensão, a experiência escolar é tão profundamente enraizada em sociedades urbanizadas, industrializadas e capitalistas que fica difícil imaginar uma infância desvinculada da escola, tamanha a naturalização da instituição escolar em nossas relações sociais (TASSINARI, 2012).

A obrigatoriedade da escola primária instituída no século XIX no ocidente tinha por objetivo incutir o ser moral em indivíduos concebidos como seres egoisticamente movidos por seus instintos e interesses próprios. Segundo Durkheim (2013), que está escrevendo na aurora da modernidade, o objetivo da educação é imprimir nas crianças o ideal de humano que, do ponto de vista intelectual, físico e moral, seja uma medida certa para todos os cidadãos, ou seja, uma função de caráter social pontual e fundamental:

A educação é a ação exercida pelas gerações adultas sobre aquelas que ainda não estão maturas para vida social. Ela tem como objetivo suscitar e desenvolver na criança um certo número de estados físicos, intelectuais e morais, exigidos tanto pelo conjunto da sociedade política quanto pelo meio específico ao qual ela está destinada em particular (DURKHEIM, 2013, p. 54).

As demandas sociais advindas da modernidade exigiram mudanças que resultaram em esquemas de domesticação de corpos (FOUCAULT, 1987). O que mudou, de fato, foram as instituições adaptadas para que essa docilidade pudesse ser preservada. Encaixada nesses moldes, assim como o espaço hospitalar, a organização militar, os quartéis e mesmo a prisão, primeiramente, passamos pela experiência escolar. Experiência indispensável para a formação do ser social. A concepção adotada para fundamentar a existência dessas instituições parte do entendimento de que a disciplina não faz parte da natureza humana. A submissão à autoridade, o exercício de disciplina, dedicação e sacrifício não fariam parte da constituição natural do indivíduo, pelo contrário. Essa seria a lacuna que a educação escolar preencheria. Diferente de animais, cuja fonte de aprendizagem se manifestaria somente para desenvolver instintos e funções naturais, a educação humana, institucionalizada, é a virtuosa criadora do ser social (DURKHEIM, 20I3, p. 55). Representa, portanto, a transição do ser humano animal para o social, isto é, domesticado. Dessa forma, dentro do conjunto de instituições disciplinares, a escola cumpre um papel indispensável no desenvolvimento de técnicas 
civilizadoras que agencia corpos úteis, produtivos e eficientes. As palavras de Sibilia resumem nosso argumento:

\begin{abstract}
Nessa imensa cruzada disciplinante, que constituiu um vetor central de nosso processo civilizador, a atividade que se desenvolvia nos colégios foi reforçada, como as denominou Foucault: do lar aos reformatórios, da fábrica aos quartéis, dos hospitais ou asilos à prisão e à universidade. Graças a esse minucioso e persistente labor mancomunado de confinamentos sucessivos, foram-se gerando subjetividades afinadas com os propósitos da época: certos modos de ser e estar no mundo que ser tornaram hegemônicos na era moderna por serem dotados de determinadas habilidades e aptidões, embora também estivessem lamentavelmente marcados por certas incapacidades e carências. Segundo as palavras do próprio Foucault, nessa época e dessa maneira se construíram corpos “dóceis e úteis”, organismos humanos treinados para trabalhar na cadeia produtiva e para se mover eficazmente nos reluzentes traçados urbanos da modernidade (SIBILIA, 20I2, p. 43).
\end{abstract}

Novamente, sabemos que muitas mudanças e acontecimentos internos e externos à instituição escolar se desdobraram ao longo do século XX. Novas pedagogias e práticas educativas, assim como uma incomensurável série de transformações políticas, econômicas e tecnológicas, para dizer o mínimo. Contudo, em pleno século XXI, em nossa pesquisa, acompanhamos a história de uma menina que a escola, por não conseguir domá-la, sugeriu sua patologização. Em termos práticos, portanto, no dia-a-dia das milhares de escolas públicas e particulares espalhadas pelo Brasil, será mesmo que aconteceram mudanças na instituição escolar? Não temos dados o suficiente para propor uma resposta a essa pergunta. De todo modo, no caso de Helena, parece que não. As escolas pelas quais ela passou continuam fundamentadas nessa base rígida de objetivos que constroem $\circ$ ser social; seguem cumprindo sua missão moral de educar, civilizar, preparar crianças para vida adulta, e é exatamente deste ponto que se origina o problema de Helena. A escola enquanto dispositivo que alinha, uniformiza, enfileira e padroniza crianças, apoiando-se em recursos analógicos, giz, quadro, boletins e horários fixos, não parece mais uma máquina adequada para as atuais crianças. Helena foi entendida como incapaz. Contudo, entendemos que as escolas de Helena foram incapazes de incluí-la. As escolas não souberam solucionar o enigma que Helena, tal como uma esfinge, representava para elas. Ao invés de repensarem suas práticas, reproduziram suas lógicas convocando a medicina como aliada.

\title{
Preenchendo lacunas: o que se perde com a escolarização
}

A realização do que significa ser aluno se dá a partir das experiências de desconforto e estranhamento ao assumir este papel. Como em um ritual de passagem, o momento do ingresso na escola, tal como Cohn argumenta (2005), marca o momento em que a criança se torna aluno, identidade essa que ultrapassa os limites delineados pelos muros da escola e segue com a pessoa mesmo depois da infância. A criança-aluna parece ser modelada de acordo com um pressuposto de 
aprendiz que carrega consigo, por sua vez, certa submissão na relação estratificada com quem ensina, o professor, e com todos os adultos em geral.

A cultura da escolarização - ou como Tassinari (20I2) sugere, seguindo Illich (1970), o "ethos escolarizado" - pode ser interpretada precisamente como esse contexto em que a criança se torna um aluno. A socialização aí é pensada e praticada enquanto aquisição de conhecimento, em que uma função da vida adulta é transmitir saberes para os que virão-a-ser, os ainda não preparados para a vida social, as crianças. Um adulto portador de cultura, preenchido com as noções que fundamentam a vida em sociedade, e a criança vindo-a-ser social, enquanto estes padrões de comportamento se reproduzem, como se a educação ou a cultura fossem algo que somente existe no mundo dos adultos e que precisa ser passada adiante, isto é, transmitida para as crianças de forma permanente e sem alterações:

[...] a cultura que vai "socializar" os indivíduos, tornando-os seres sociais. Parte-se do princípio de um reino natural e externo a ser "socializado" pelo mundo da cultura ou do social. A educação das crianças foi pensada a partir desse modelo, na medida em que elas eram consideradas parte de um mundo natural, [...] a noção de socialização tem origem no século XIX e está presente em todos os modelos europeus que visavam a educação infantil do século $X X$, desde o de Freud ao de Skinner. Além disso, ela foi construída a partir de uma noção cristã da Idade Média de que a criança deveria ser moldada como a argila ou o betume. A partir da sua inserção gradativa na sociedade as crianças iriam se tornando seres sociais. Aprenderiam a falar, a andar, a comer à mesa e muito mais tarde teriam uma profissão que definiria seu lugar no mundo social. Doravante, ela será tanto mais social quanto mais bem-sucedida for no mundo social. A criança seria, gradativamente, "moldada" pelos adultos (PIRES, 2010, p. 147).

Diante dessa premissa, a escolarização vai além de um projeto pedagógico. Ela invade e se apropria de toda aprendizagem, isto é, de todo ensino, ou a confusão que norteia essas duas ideias: a criança é escolarizada para amalgamar aprendizagem com ensino, passar de ano com educação, boas notas com competência. As sociedades escolarizadas são articuladas em um contexto repleto de abstração, no qual a escola detém o monopólio da educação, a única capaz de educar. Os outros espaços, portanto, não servem para tanto. Neste modelo social, entende-se que "[...] não se aprende fora da escola" (TASSINARI, 20I2, p. 280). Logo, a reflexão levantada aqui não pretende questionar projetos pedagógicos, ou mesmo a importância social da instituição escolar, mas, antes, almeja entender o que a escola perde com a cultura da escolarização. Tal reflexão desdobra-se da percepção empírica de que a lacuna escancarada por Helena expõe uma tomada de decisão que reforça e reproduz tal cultura. Afinal, o problema que Helena coloca para a escola, na verdade, está resolvido desde o início: a patologização capacitista ${ }^{13}$ da criança na exigência de um diagnóstico.

\footnotetext{
${ }^{13}$ Capacitismo é o termo adotado para se referir aos preconceitos e às práticas excludentes de pessoas com deficiência. Sobre a origem do termo, ver Mello (2016).
} 
Para além dos aspectos biológicos, o corpo está intrinsecamente conectado ao campo social, político e cultural, como argumentado diversas vezes no percurso da antropologia e especialmente na obra de Foucault (1987). Essas relações de poder exercidas sobre o corpo estão diretamente ligadas à sua dominação, domesticação e adestramento, ou ainda, em termos mais antropológicos, na necessidade de civilizar corpos socialmente concebidos como selvagens. Vigiados, nossos corpos permeiam os campos sociais, ou o que Foucault chama de "aparelhos de produção", para que este processo aconteça de forma gradual e orgânica no intuito de produzir e suprir demandas. Corpos obedientes, medicados, ou mesmo punidos, se necessário. Esta é a microfísica do poder, mecanismo que, na perspectiva foucaultiana, inscreve-se no processo de construção da alma moderna. Ora, se a cultura da escolarização é pontualmente a clássica noção de educação posta por intelectuais dos séculos XVIII e XIX, aqui ilustrados por Durkheim, por consequência, ela opera de forma direta com a concepção de controle de corpos posta por Foucault. Em outras palavras, esta foi a decisão tomada pela escola: ao não corresponder da forma esperada, Helena foi entendida como um problema.

O estranhamento ocasionado pela realização do que é ser aluno é mais significativo em algumas crianças do que em outras. A reprodução da cultura da escolarização, no entanto, parece ser incapaz de compreender as nuances ocasionadas por essas diferenças e, consequentemente, tende a deslegitimar ou mesmo excluir a subjetividade de algumas crianças. Não se trata simplesmente da Helena ser boa ou não na leitura, ou mesmo se ela está mais interessada em seu estojo do que na aula, mas sobre como a não correspondência com a padronização exigida é tomada como um problema, uma negativa, como demonstra Walkerdine: "Meu argumento, portanto, não é simplesmente o de que as garotas vão mal em matemática ou em raciocínio, mas que a 'verdade' do desenvolvimento infantil patologiza e define o seu desenvolvimento de uma forma que ele tem que ser lido como ruim" (WALKERDINE, 1995 apud TASSINARI, 2012, p. 279). É dessa forma que a lacuna aberta pela incompatibilidade de Helena e a escola é preenchida; é assim que chegamos em - ou buscamos incansavelmente - um diagnóstico. $O$ "ethos escolarizado" imprime desde o primeiro recado escrito na agenda de Helena: o estojo reflete em muito mais do que uma falta de atenção por parte da criança, traduzindo-se na reprodução da cultura da escolarização. Os encaminhamentos médicos, a jornada pelo fim da fala "infantilizada" de uma criança de sete anos, a espera por um diagnóstico médico que pudesse comprovar que o problema está na criança, não na escola. Eis o que perdemos com a cultura da escolarização: nossa Helena. Em troca, ganhamos a Helena delas, das escolas. Contudo, todas essas Helenas estão em um mesmo corpo e são uma mesma subjetividade.

\section{Considerações finais}

Olhar de professor, Ponta Grossa, v. 24, p. I-23, e- I845I.094, 202 I.

Disponível em <https://revistas2.uepg.br/index.php/olhardeprofessor> 
A escola reproduziu a si mesma diante de Helena. Em uma oportunidade de transformação para acolhê-la, exigiu-se sua padronização. Dentre a escolha de entender Helena como uma possibilidade, tornaram-na um problema. Se a maioria atinge uma demanda esperada, então, encaminhamentos e laudos são exigidos para a que não atingiu. $A$ escola manteve a ideia de criança como tabula rasa. Como um selvagem que se recusa à civilização, Helena não se encaixou no modelo de aluna. Contudo, tal situação foi interpretada pelas escolas como incapacidade de aprendizado. Mais ainda, Helena foi responsabilizada pelo seu fracasso.

Diante da imposição de que não existe outra possibilidade de aprendizagem se não em ambiente escolar, Helena aprendeu a ler em meio a uma pandemia, afastada da escola, jogando online em seu celular. No momento em que este artigo foi escrito, Helena, aos dez anos de idade, demonstra um conhecimento em inglês muito mais avançado do que o esperado, adquirido através das músicas, desenhos e filmes que gosta, tendo em vista que suas escolas não ofertam aulas de língua estrangeira. Enquanto sua saúde física e mental estava sendo questionada, Helena demonstrou capacidade de raciocínio, desenhando, escrevendo e animando histórias que cria por meio de seu celular. Perante a angústia de seus familiares, que buscavam perceber os problemas que a escola apontava, Helena demonstrava-se não muito diferente das demais crianças da família. $O$ interesse moveu Helena, expondo-a como uma criança perfeitamente capaz de aprender; infortunadamente, a escola não reconheceu e muito menos estimulou seus interesses. Pelo contrário, a apontou como incapaz de fazer - que se pedia, tal como uma deficiente que exige auxílios externos, laudos, diagnósticos e medicamentos para ser uma aluna. Tendo a oportunidade de se transformar para incluí-la, a escola não soube lidar com suas diferenças. Nesse emaranhado estranho de interações embaraçosas e incompatíveis, a relação dessa criança com a escolarização expõe uma escola que não está pronta para as diferenças. A cultura da escolarização, dentre todas suas características, parece não reconhecer a oportunidade na relação com as diversidades. Com Helena, no fundo, o que se reproduziu foi o mesmo.

O caso de Helena, além de nos permitir avançar uma teoria relacional do aprendizado, indica que, se os agentes educacionais e de saúde tiverem mais consciência acerca dos efeitos determinantes de suas palavras e seus atos nos corpos e vidas das crianças, talvez eles possam manuseá-las e articulálos com mais cuidado. Afinal, suas perspectivas, mesmo importantes, precisam ser balizadas pela percepção das particularidades da criança. Talvez, eis aí um modo de transformar casos de exclusão em relatos de inclusão escolar: com as escolas e seus agentes considerando efetivamente que as crianças são mais do que alunas.

Queremos acreditar que esta percepção expandida dos alunos como pessoas é a maior potencialidade que as pesquisas etnográficas podem oferecer aos estudos de inclusão e exclusão escolares. Trabalhando e realizando pesquisas em ambientes escolares, nossas atenções voltam-se aos 
aspectos estruturantes dessas instituições: as aulas, os materiais didáticos, os currículos, as salas, os processos de ensino e aprendizagem e assim por diante. E é assim mesmo que temos de proceder, uma vez que são esses aspectos que determinam a realidade escolar. Contudo, não podemos deixar de notar que as escolas também são estruturadas por alunos, ou melhor, por pessoas que ocupam esse lugar historicamente concebido como subalterno nas escolas. Este é o lembrete que as etnografias com alunos podem fazer, isto é, o de demonstrar que os discursos escolares não explicam completamente as subjetividades das pessoas que participam das realidades escolares como alunos. Ao deslocar a perspectiva de análise da escola para as pessoas que nela estão como alunos, contemplamos com mais ênfase o que a antropologia entende por diferenças e singularidades, ou aquilo que João Biehl (2005) afirmou como o caráter inacabado de todo ser, ou seja, a ideia de que os sujeitos não são completamente determinados pelas instituições e discursos sociais. Deste ponto de vista, a inclusão e a exclusão podem ser analisadas não só como arranjos escolares, mas, também, como formas de cuidado ou desdenho das subjetividades de crianças e jovens agenciados como alunos.

\section{Referências}

APA (Associação Americana de Psiquiatria). Diagnostic and Statistical Manual of Mental Disorders, Fifth Edition (DSM-V). Arlington: American Psychiatric Association, 2013.

BIEHL, J. Vita: life in a zone of abandonment. Berkeley: University of California Press, 2005.

BONADIO, R. A. A.; MORI, N. N. R. Transtorno de déficit de atenção/hiperatividade: diagnóstico da prática pedagógica. Maringá: Editora da UEM, 2013.

BORBA, M. P. Entre produtividades, compassos e dispersões: mobilizações de atenção e cuidado no cotidiano escolar. Tese (Doutorado em Antropologia) - Instituto de Ciências Humanas e Filosofia, Universidade Federal Fluminense. Niterói, 2019.

BOSA, C. A.; SCHMIDT, C. Estresse e autoeficácia em mães de indivíduos com autismo. Arquivos Brasileiros de Psicologia, v. 59, 2007. Disponível em:

http://pepsic.bvsalud.org/scielo.php?script=sci_arttext\&pid=SI809-52672007000200008. Acesso em: 21 dez. 2021.

BREUER, J.; BENTE, G. Why so serious? On the Relation of Serious Games and Learning. Journal for Computer Game Culture, v. 4, n. I, 2010. Disponível em: https://hal.archives-ouvertes.fr/hal00692052/document. Acesso em: 21 dez. 2021.

CAMPOY, L. Sociedade do autismo, etnografia de vida. Tese (Doutorado em Antropologia) Instituto de Filosofia e Ciências Sociais, Universidade Federal do Rio de Janeiro. Rio de Janeiro, 2017.

CARNIEL, F. Agenciar palavras, fabricar sujeitos: sentidos da educação inclusiva no Paraná.

Horizontes Antropológicos, v. 24, n. 50. Porto Alegre, 2018. Disponível em:

https://www.scielo.br/j/ha/a/GBbYFpX99YGGDTyr8HkzNBg/?lang=pt. Acesso em: 21 dez. 2021.

COHN, C. Antropologia da criança. Rio de Janeiro: Zahar, 2005. 
COSTA, D.; PAULA, J.; MALLOY-DINIZ, L.; ROMANO-SILVA, M.; MIRANDA, D. Avaliação do instrumento SNAP-IV pelos pais no transtorno de déficit de atenção/hiperatividade: acurácia em uma amostra clínica de TDAH, validade e confiabilidade em uma amostra brasileira. Jornal de Pediatria, v. 95, n. 6, 2019. Disponível em:

https://www.sciencedirect.com/science/article/pii/S002 I7557/83047/6. Acesso em: I5 jul. 202 I.

DAMATTA, R. O oficio de etnólogo ou como ter anthropological blues. In: NUNES, E. de O. A aventura sociológica. Rio de Janeiro: Zahar, 1978.

DAS, V. Vida e palavras: a violência e sua descida ao ordinário. São Paulo: Editora Unifesp, 2020.

DOUGLAS, M. Pureza e perigo. São Paulo: Perspectiva, 2010.

DURKHEIM, É. Educação e sociologia. Rio de Janeiro: Editora Vozes, 2013.

ERIKSEN, T. H.; NIELSEN, F. S. História da antropologia. Petrópolis: Editora Vozes, 2013.

FARIA, M. J.; COLPANI, R. Avaliação técnica e pedagógica do jogo sério "Joy e as letrinhas".

Renote, v. 16, n. I, 2018. Disponível em: https://seer.ufrgs.br/renote/article/view/85877. Acesso em: 21 dez. 2021.

FIETZ, H. M. Construindo futuros, provocando o presente: cuidado familiar, moradias assistidas e temporalidades na gestão cotidiana da deficiência intelectual no Brasil. Tese (Doutorado em Antropologia) - Instituto de Filosofia e Ciências Humanas, Universidade Federal do Rio Grande do Sul. Porto Alegre, 2020.

FOUCAULT, M. O governo de si e dos outros. São Paulo: Martins Fontes, 2010.

FOUCAULT, M. Vigiar e Punir: nascimento da prisão. Petrópolis: Vozes, 1987.

GABARDINO, M. I. Queixa escolar e gênero: a (des)construção de estereótipos na educação.

Revista Brasileira de Educação, v. 26, 202I. Disponível em: https://doi.org// 0.1590/SI4I32478202I2600II. Acesso em: 20 dez. 2021.

GAMA, F. A autoetnografia como método criativo: experimentações com a esclerose múltipla.

Anuário Antropológico, v .45, n. 2, 2020. Disponível em: http://journals.openedition.org/aa/5872.

Acesso em: 15 jul. 2021

IILICH, I. Deschooling society. Nova York: Harper Colophon, 1970.

MELLO, A. G. Deficiência, incapacidade e vulnerabilidade: do capacitismo ou a preeminência capacitista e biomédica do Comitê de Ética em Pesquisa da UFSC. Ciênc. Saúde Colet., v. 21 , n. 10, 2016. Disponível em:

https://www.scielo.br/j/csc/a/J959p5hgv5TYZgWbKvspRtF/?format=pdf\&lang=pt. Acesso em: 19 nov. 2021.

SCHUCH, P.; VÍCTORA, C. G.; SILVA, S. B. As políticas de inclusão como problemática de engajamento antropológico. Horizontes Antropológicos, v. 24, n. 50. Porto Alegre, 2018. Disponível em: https://www.scielo.br/j/ha/a/fYZ6DqmnZwbyRFTMP5W6qwC/?format=pdf\&lang=pt. Acesso em: 21 dez. 2021. 
SIBILIA, P. Redes ou paredes: a escola em tempos de dispersão. Rio de Janeiro: Contraponto, 2012.

SILVA, J. J.; REBOUÇAS, A. D. D. S. Avaliando o Uso do Aplicativo "Embaralhado" no Processo de Alfabetização. Renote, v. 16, n. I, 2018. Disponível em:

https://seer.ufrgs.br/renote/article/view/8600I. Acesso em: 21 dez. 2021.

SPIVAK, G. C. Pode o subalterno falar? Belo Horizonte: Editora UFMG, 2010.

TASSINARI, A. I. A sociedade contra a escola. In: TASSINARI, A. I.; GRANDO, B. S.;

ALBUQUERQUE, M. A. S. (Orgs). Educação Indígena: Reflexões sobre noções nativas de infância, aprendizagem e escolarização. Florianópolis: Editora da UFSC, 2012.

PEIRANO, M. Etnografia não é método. Horizontes antropológicos, Porto Alegre, v. 20, n. 42, p. 377-39I, dez. 2014. Disponível em:

http://www.scielo.br/scielo.php?script=sci_arttext\&pid=SO I 047 I $8320 \mid 4000200015 \& \operatorname{lng}=$ en\&nrm=iso.

Acesso em: 03 jul. 202I.

PIRES, F. O que as crianças podem fazer pela antropologia? Horizontes antropológicos, Porto Alegre, v. 16, n. 34, p. 137-157, dez. 2010. Disponível em:

http://www.scielo.br/scielo.php?script=sci_arttext\&pid=SO $1047 \mid$ I $832010000200007 \& \operatorname{lng}=$ en\&nrm=iso.

Acesso em: 14 jul. 2021.

Recebido em: 16 de julho de 2021 .

Versão corrigida recebida em: 22 de novembro de 2021.

Aceito em: 10 de dezembro de 2021 .

Publicado online em: 22 de dezembro de 202I. 